\title{
Granulosa Cell Tumor Associated with Occult Hyperadrenocorticism in a Yorkshire Terrier Bitch
}

\author{
Priscilla Deluchi', Gabriela Reis Ledur'2, Saulo Petinatti Pavarini ${ }^{3}$ Álan Gomes Pöppl2,4
}

\begin{abstract}
Background: Hyperadrenocorticism (HAC), is considered a set of symptoms due to excessive exposure to cortisol. Naturally occurring HAC is most often related to pituitary tumors (pituitary-dependent HAC - PDH). Occult HAC, is referred as a clinical picture highly consistent with HAC; however, routine screening tests are negative. In addition, one or more steroids are elevated following administration of adrenocorticotrophic hormone (ACTH). Ovarian granulosa cell tumors, can produce steroids leading to paraneoplastic syndromes. The objective of this study was to report an unpublished case of ovarian granulosa cell tumor associated with occult hyperadrenocorticism in a Yorkshire Terrier.

Case: A 13-year-old intact female dog, Yorkshire Terrier, was brought for consultation with slight weight loss, polyuria, polydipsia, irregular estrous cycles, increased abdominal volume and thin coat. On physical examination the animal was gasping and presented severe periodontal disease, bulging abdomen, alopecia and skin hyperpigmentation. Complete blood count presented no changes; however, serum biochemistry evaluation highlighted hyperalbuminemia, hypertriglyceridemia, alkaline phosphatase increased activity, and urinary specific gravity and creatinine below reference values. On abdominal ultrasonography left adrenal gland measured $2.08 \mathrm{~cm} \times 1.08 \mathrm{~cm}$ and the right adrenal gland measured $2.11 \mathrm{~cm}$ x $0.84 \mathrm{~cm}$, indicating bilateral adrenomegaly compatible with PDH. In the hypogastric abdomen, a large heterogeneous hypoechogenic mass was also observed, with areas of cystic cavities, measuring $5.80 \mathrm{~cm}$ x $7.30 \mathrm{~cm}$. A low dose dexamethasone suppression test (LDDST) was performed, due to PDH suspicion. The test did not confirm HAC, suspecting, then, to be a case of occult/atypical HAC. Due to the strong clinical suspicion, and owner financial problems for further investigated occult HAC, trilostane treatment was initiated. Approximately one month after starting treatment, an ACTH stimulation test (AST) for cortisol and 17-hydroxyprogesterone (17-OHP) determination was performed, revealing high values for both hormones. Exploratory laparotomy was indicated due to the tumor image on hypogastric region visualized on abdominal ultrasonography. A cranial pole mass of the left ovary measuring $8.5 \times 7.0 \times 4.5 \mathrm{~cm}$, of friable consistency and brownish color, was removed through ovariohysterectomy. A granulosa cell tumor on left ovary, as well as leiomyoma and cystic endometrial hyperplasia in the uterus, became clear through histopathological examination. Trilostane treatment was sustained after surgery. Few weeks later, the patient presented a clinical picture suggestive of hypoadrenocorticism, associated with a low sodium:potassium ratio (25:1), and AST results (basal and post-ACTH cortisol) below reference range, confirming Addisonian' crises. The patient deceives within two days.

Discussion: Granulosa cell tumors can produce estrogen and progesterone, as well as other steroids, leading to paraneoplastic syndromes with peculiar clinical presentations. Steroids transport in plasma occurs via specific carrier proteins. Increased production of other steroid hormones may result in higher concentration of free cortisol, thus leading to clinical manifestations of hypercortisolism. As 17-OHP is one of the precursors in cortisol synthesis and has been shown elevated on AST, it can be assumed that altered steroid hormone levels due to the granulosa cell tumor interfered on cortisol biodisponibility, leading to HAC signs. Dexamethasone suppression test results indicated that pituitary-adrenal axis was responsive to negative feedback. The Addisonian crises after tumor removal indicate that the main source for systemic excessive cortisol effects was the eminent steroid secretion by the granulosa cell tumor.
\end{abstract}

Keywords: ovarium tumor, Cushing's syndrome, atypical hyperadrenocorticism, steroidogenesis. 


\section{INTRODUCTION}

Hyperadrenocorticism (HAC), also called Cushing's syndrome, is considered on of the most prevalent dogs' endocrinopathies $[3,15,16]$, and is defined as a myriad of clinical signs resultant of cortisol effects' excessive exposure [7]. Closely $80 \%$ of naturally occurring HAC cases results of excessive adrenocorticotrophic hormone (ACTH) by pituitary corticotrophinomas, being characterized as pituitary-dependent HAC (PDH). The last 15 to $20 \%$ of the cases are referred to functional adrenocortical tumors, ACTH-independent $[7,8]$. A less common spontaneous HAC cause is the atypical/occult form; followed by even lesser usual forms such as ectopic ACTH syndrome, food-dependent HAC, and adrenocortical tumor sexual hormones over secretion $[8,13]$

Occult HAC, also called atypical, is referred as a clinical picture highly consistent with HAC (clinical signals, hematology, serum biochemistry, urinalysis, and ultrasound); however, routine screening tests are negative, such as the low dose dexamethasone suppression test (LDDST) and ACTH stimulation test (AST). In addition, one or more steroids are elevated following administration of adrenocorticotrophic hormone (ACTH) [1]. Ovarian tumors can promote paraneoplastic syndromes related to altered tumor steroidogenesis $[4,6,10,14]$. By this moment, in dogs, there is only one ovarian tumor report, suggested to be a luteoma, associated do HAC in a Rottweiler bitch [17]. The aim of this work was to report an unpublished ovarian granulosa cell tumor associated with occult HAC in a Yorkshire Terrier bitch.

\section{CASE}

A 13-year-old female intact, Yorkshire Terrier dog was brought to the Hospital de Clínicas Veterinárias (HCV) of the Universidade Federal do Rio Grande do Sul (UFRGS) due to discrete weight loss, polyuria and polydipsia, and irregular estrous cycle. At physical examination the patient showed tachypnea, halitosis and severe periodontal disease associated with submandibular lymph adenomegaly. Moreover, a bulged abdomen with ventral skin showing telangiectasis, alopecic and hypotrichotic areas, hyperpigmentation, and small punctiform calcinosis cutis focus were evident (Figure 1).

A minimum data base (complete blood count, serum biochemistry, urinalysis, urinary culture, and ultrasound) was obtained. Serum biochemistry after 12 $\mathrm{h}$ fasting main results showed hyperalbuminemia $(3.7 \mathrm{~g} /$ $\mathrm{dL}$ - reference interval: 2.6 to $3.3 \mathrm{~g} / \mathrm{dL}$ ), hyperphosphatasia (371 U/L - reference interval: < $156 \mathrm{U} / \mathrm{L}$ ), discreet hypertriglyceridemia $(142 \mathrm{mg} / \mathrm{dL}$ - reference interval: 32 to $138 \mathrm{mg} / \mathrm{dL})$ and reduced serum creatinine (0.47 $\mathrm{mg} / \mathrm{dL}$ - reference interval: 0.5 to $1.5 \mathrm{mg} / \mathrm{dL})$. Complete blood count did not show any alteration. However, urinalysis showed urine specific gravity $1,022 \mathrm{~g} / \mathrm{L}$ (reference interval: $>1,035)$ without any other alteration. Also, there was no bacterial growth in urine culture.

Abdominal ultrasound revealed urinary bladder with thickened walls and hyperechoic kidneys, with corticomedullary definition loss. Left adrenal gland measure $1.72 \times 0.7 \mathrm{~cm}$ while right adrenal gland measure $2.11 \times 0.84 \mathrm{~cm}$, compatible with bilateral adrenomegaly. Yet, discrete hepatomegaly and biliary bladder filled by hyperechoic biliary sludge with suspended hyperechoic points became evident. Furthermore, at hypogastric abdomen a large hypoechoic heterogeneous mass, with cystic cavities, and measuring about $5.63 \mathrm{~cm} \mathrm{x} 7.66 \mathrm{~cm}$ was identified. Therefore, a thoracic X-ray for metastasis investigation and an echocardiography were requested for a near future surgical planning. A discreet mitral valve insufficiency with preserved systolic function was documented at echocardiography, and no metastatic evidence was observed in pulmonary fields' X-ray.

Due to elevated HAC suspicion promoted by bitch's clinical picture, a LDDST was performed to investigate a possible PDH. All cortisol determinations were made by radioimmunoassay. The LDDST results showed a $1.49 \mu \mathrm{g} / \mathrm{dL}$ basal cortisol (reference interval: 0.5 to $6 \mu \mathrm{g}$ / $\mathrm{dL}$ ), 4-h post-dexamethasone cortisol $0.39 \mu \mathrm{g} / \mathrm{dL}$ (reference interval: $<1 \mu \mathrm{g} / \mathrm{dL}$ ), and 8 -h post-dexamethasone cortisol $0.06 \mu \mathrm{g} / \mathrm{dL}$ (reference interval: $<1 \mu \mathrm{g} / \mathrm{dL}$ ), consonant with a negative PDH result. Because of the dog' typical HAC picture, and owner financial scarceness for further hormonal evaluation, an occult HAC diagnosis was assumed by the medical team. Trilostane $\left(\text { Vetory }{ }^{\circledR}\right)^{1}$ treatment was then started, at $1 \mathrm{mg} / \mathrm{kg}$ dose, each $12 \mathrm{~h}$ with food, aiming to prepare the patient for an exploratory laparotomy to investigate and remove the hypogastric abdominal mass identified at ultrasound.

One month after treatment start, an AST was performed to access adrenocortical reserve due trilostane treatment and treatment effectiveness, by means of an intravenous administration of $5 \mu \mathrm{g} / \mathrm{kg}$ synthetic ACTH (Synacthen $\left.{ }^{\circledR} 250 \mu \mathrm{g} / \mathrm{mL}\right)^{2}$. To further test for occult HAC, $17 \alpha$-hydroxy-progesterone (17-OHP) concentration was 
also measured after ACTH administration. The patient showed a $9.88 \mu \mathrm{g} / \mathrm{dL}$ basal cortisol (reference interval: 0.5 to $6 \mu \mathrm{g} / \mathrm{dL}$ ), 1-h post-ACTH cortisol $13.95 \mu \mathrm{g} / \mathrm{dL}$ (reference interval: 6 to $17 \mu \mathrm{g} / \mathrm{dL}$, target range for patients in HAC medical treatment: 2 to $6 \mu \mathrm{g} / \mathrm{dL}$ ), and post-ACTH 17-OHP 7.59 ng/mL (reference interval for intact female: $<4.2 \mathrm{ng} / \mathrm{mL}$ ). In the same clinical evaluation, the owner reported abdominal pain and additional abdominal bulge, associated with dermatological clinical signals persistence as well as polyuria and polydipsia. Abdominal ultrasound was repeated and confirmed the presence of a mass with $5.63 \mathrm{~cm} \times 7.66 \mathrm{~cm}$ at hypogastric abdomen. The patient was then set out for exploratory laparotomy. Trilostane therapy was interrupted $24 \mathrm{~h}$ prior surgery, and then recovered again $24 \mathrm{~h}$ after surgical intervention.

During surgery, a cranial mass at left ovary was localized and an ovary-hysterectomy was done. The material was sent for histopathological evaluation and showed a friable consistency, brownish color, and measure $8.5 \mathrm{~cm}$ x $7.0 \mathrm{~cm}$ x $4.5 \mathrm{~cm}$. Uterine lumen has several cysts filled by a plentiful brown mucous material. At right uterine horn medium third, a polypoid-like nodule, measuring $2.0 \mathrm{~cm} \times 2.0 \mathrm{~cm}$, whitish, encapsulated, and firm at cut was also found (Figure 2). Histopathological evaluation revealed a granulosa cell tumor at left ovary (Figure 3A), associated with a leiomyoma, and cystic endometrial hyperplasia (Figure 3B).

Two weeks after surgery the patient come back to the hospital due to severe prostration and hyporexia. Polyuria and polydipsia achieved remission, and the bitch was showing pale mucous membranes. Blood samples were collected, and an AST was performed together with an abdominal ultrasound. A normocytic normochromic anemia was observed (erythrocyte $4.23 \times 10^{6} / \mathrm{mm}^{3}$, hemoglobin $10.3 \mathrm{~g} / \mathrm{dL}$, hematocrit $33 \%$, MCV $78 \mathrm{Fl}$, MCHC 31.2\%) associated with a serum sodium of 149 $\mathrm{mEq} / \mathrm{L}$ (reference interval: $135-150 \mathrm{mEq} / \mathrm{L}$ ), and a mild hyperkalemia of $5.8 \mathrm{mEq} / \mathrm{L}$ (reference interval: 3,5-5 $\mathrm{mEq} / \mathrm{L}$ ), with a resultant $25: 1 \mathrm{Na}: \mathrm{K}$ ratio (reference interval: > 27:1). These results suggest hypoadrenocorticism occurrence. No other hematological (leukogram, platelets count) or serum biochemistry abnormalities (albumin $3 \mathrm{~g} /$ $\mathrm{dL}$, ALT $44 \mathrm{U} / \mathrm{L}$, total cholesterol $139 \mathrm{mg} / \mathrm{dL}$, creatinine $0.66 \mathrm{mg} / \mathrm{dL}$, alkaline phosphatase $50 \mathrm{U} / \mathrm{L}$, urea $41 \mathrm{mg} /$ $\mathrm{dL}$, and triglycerides $65 \mathrm{mg} / \mathrm{dL}$ ) were documented. At abdominal ultrasound, a caudal cava vein thrombus was observed with partial blood flux interruption, liver congestion and small amount of cavity free liquid. Immediate interruption of trilostane treatment was recommended, as well as hospital internment for fluids administration and overall stabilization of the patient. Despite that, the patient deceived in less than 48 hours, and a necropsy was not authorized by the owners. Lately, AST results showed a basal cortisol of $1 \mu \mathrm{g} / \mathrm{dL}$ (reference interval: 0.5 to $6 \mu \mathrm{g} / \mathrm{dL}$ ), one-hour post-ACTH cortisol $1.2 \mu \mathrm{g} /$ $\mathrm{dL}$ (reference interval: 6 to $17 \mu \mathrm{g} / \mathrm{dL}$, target range for patients in HAC medical treatment: 2 to $6 \mu \mathrm{g} / \mathrm{dL}$ ), and post-ACTH 17-OHP $0.16 \mathrm{ng} / \mathrm{mL}$ (reference interval for spayed female: $<1.6 \mathrm{ng} / \mathrm{mL}$ ). The clinical picture associated with laboratory results confirmed the hypoadrenocorticism, and the 17-OHP overproduction control after ovary-hysterectomy.

\section{DISCUSSION}

A possible relationship between ovarian tumors and HAC is being discussed for years in human medicine $[14,18]$. However, there is paucity of ovarian tumor case reports linked to endocrinopathies in veterinary literature, and only one case of HAC associated with an ovarian luteoma in a Rottweiler was found [17]. Granulosa cell tumors are gonadal-stromal neoplasia originated from the sexual ovarian cordon and represent approximately $50 \%$ of bitches' ovarian tumors. These neoplastic cells can secrete estrogens and progestogens, among other steroid precursors, leading to paraneoplastic syndromes such as estrogen-related pancytopenia, progesterone-related diabetes mellitus, cystic endometrial hyperplasia, pyometra, and persistent estrus. Furthermore, in over $20 \%$ of the cases, a malignant behavior became evident with metastatic disease in different organs $[4,6,10]$.

In the present case, cystic endometrial hyperplasia was found in post-mortem examination, and irregular estrus cycle was reported by the owners. Nevertheless, no evidence of metastasis was found in the imaging exams performed, or even other paraneoplastic syndromes besides occult HAC. However, the thrombus at caudal cava vein identified only post-surgery was a potential consequence of tumor invasion throughout phrenic-abdominal vein, and is considered a highly malignant behavior $[6,10]$. Other possible origin for the thrombus is the fact that Cushing dog's tend to thromboembolic problems due to stimuli for coagulation factors and anticoagulant factors activity diminishment [13]. Unfortunately, the fact that the owners did not authorized necropsy make impossible to clear up this question. 


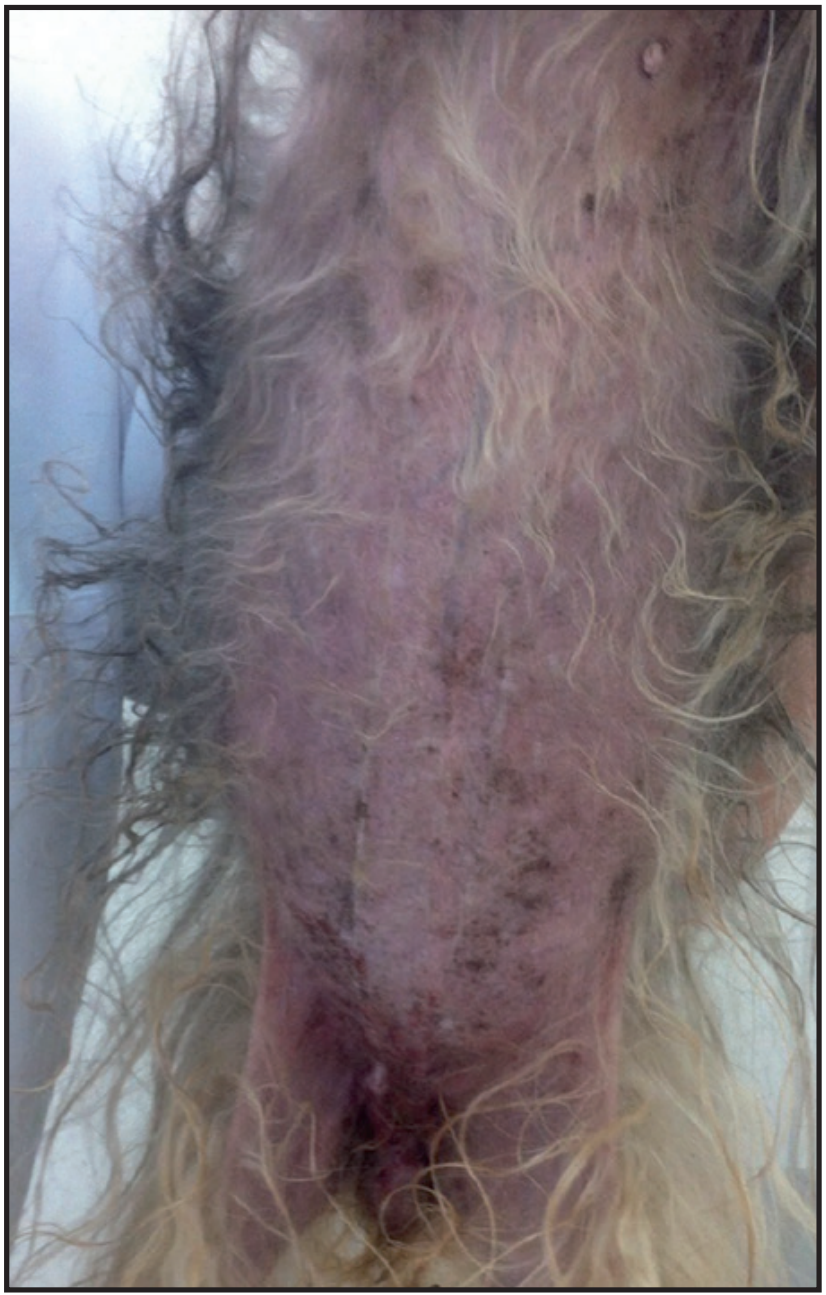

Figure 1. Yorkshire Terrier bitch ventral view. Abdominal enlargement, telangiectasis, comedones, and hypotrichosis at physical examination.

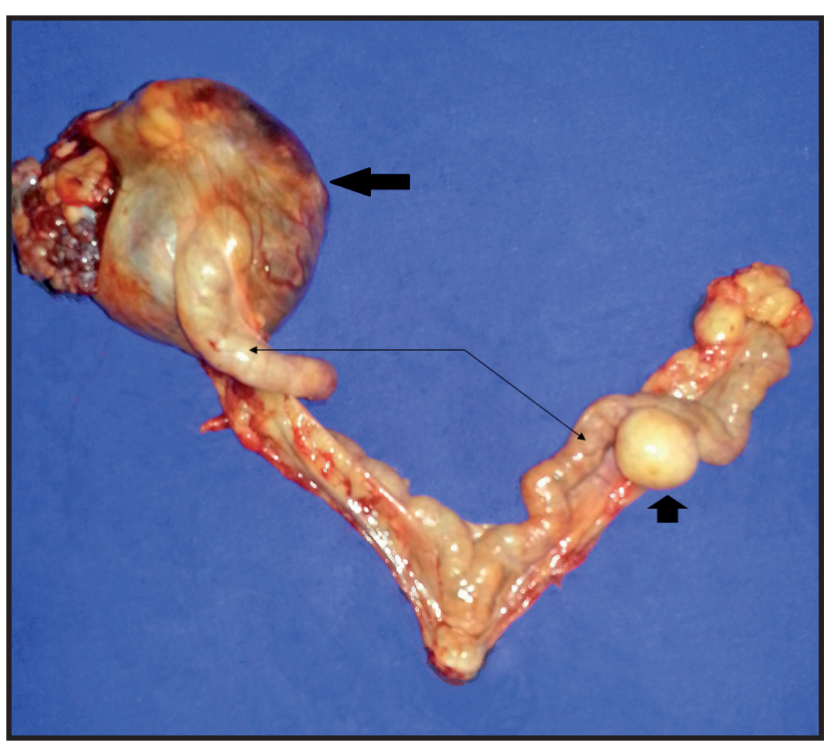

Figure 2. Uterine and ovarian macroscopic appearance after surgical removal. Large arrow: neoplastic formation poorly delimited at left ovarium's cranial pole measuring $8.5 \times 7.0 \times 4.5 \mathrm{~cm}$. Small arrow: whitish, encapsulated, polypoid-like nodule at right uterine horn measuring $2.0 \mathrm{x}$ $2.0 \mathrm{~cm}$. Thin arrows: cystic hyperplasia disseminated over uterine horns.
Steroid hormones have cholesterol as precursor, and the steroidogenesis to active hormones occurs at adrenal cortex and gonads. While in adrenal cortices cholesterol is converted to glucocorticoids, mineralocorticoids, and androgens, the gonadal steroidogenesis produces estrogens, progestogens, and androgens [8]. Steroids plasma transport, including cortisol, occurs by means of specific binding proteins, and only free steroids can enter cells and activate hormone receptors. By this way, in cases with increased steroidal hormones secretion, more cortisol may become free of binding proteins, leading to HAC clinical manifestations, despite cortisol results within reference values in dynamic tests such as LDDST and AST [1,7]. This hypothesis is supported in the present case due to elevated 17-OHP concentration after ACTH stimulation. Serum progesterone concentrations correlate with 17-OHP serum concentration during luteal phase in women [5], and the same is expected in bitches. Isolated 17-OHP elevations lost specificity for HAC diagnosis and may be elevated in patients in treatment with trilostane. However, the relevant reduction in 17-OHP after ovary-hysterectomy strongly supports the ovarian origin for these steroidal imbalance $[1,3,5,7,9,12]$.

HAC diagnosis is based on the presence of typical clinical signals, laboratorial abnormalities, imaging, and pituitary-adrenal cortex axis function tests $[2,3,5]$. This particular patient did show many hypercortisolemic-related symptoms such as polyuria and polydipsia, abdominal enlargement, telangiectasis, skin atrophy and hyperpigmentation, hypotrichosis, and calcinosis cutis [7]. Indeed, this set of skin atrophy, telangiectasis and calcinosis cutis may be considered pathognomonic for HAC in dogs [2,7,8]. Moreover, some common laboratory abnormalities in dogs with HAC were documented in the present case (alkaline phosphatase activity elevation, hypertriglyceridemia, and reduced serum creatinine) [2,3]. Ultrasound findings also contributed for the HAC characterization due to hepatomegaly and bilateral adrenomegaly $[2,3,7,8]$. The LDDST is considered by many authors, and by the consensus of the American College of Veterinary Internal Medicine as the best screening teste for HAC. The test is highly sensitive; however, little specific. By this way, it is recommended that HAC diagnosis should be based mainly in the presence of clinical manifestations, laboratory abnormalities, and imaging, associated with compatible endocrine tests [2,3]. The diagnosis of occult HAC was assumed due to the patient's clinical picture 


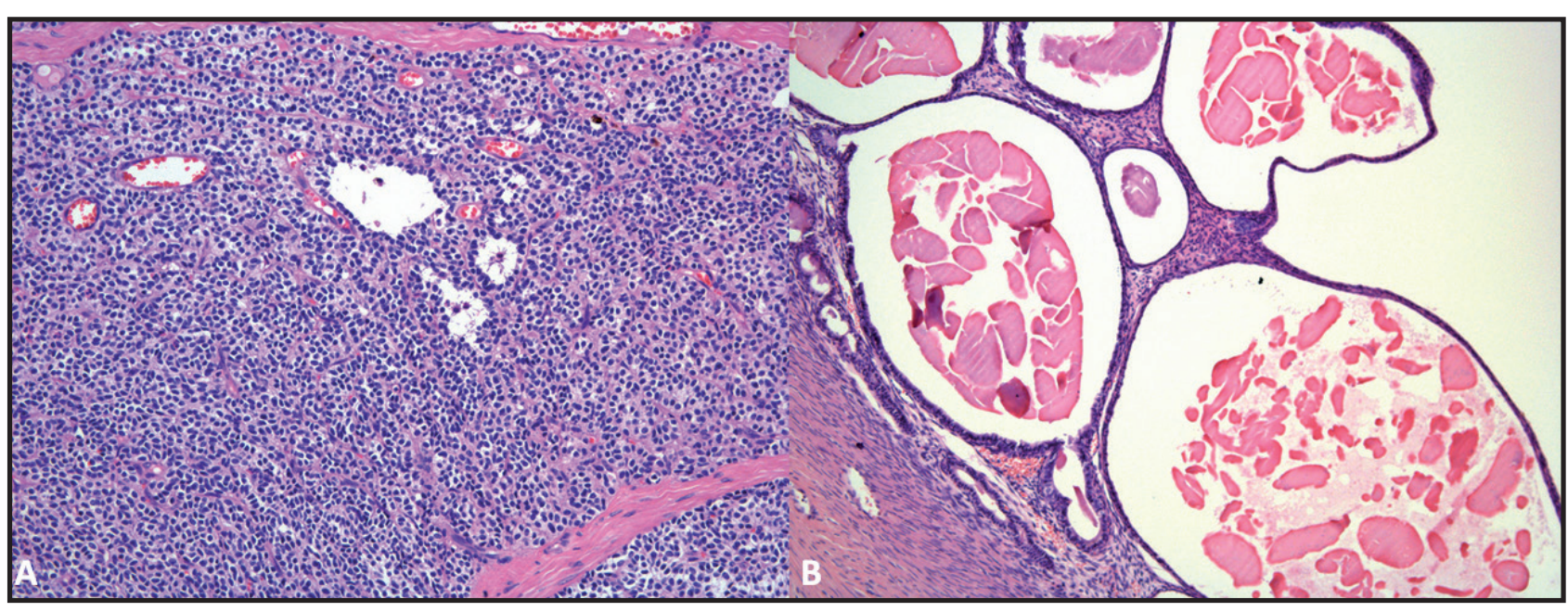

Figure 3. A- Ovarian granulosa cell tumor. Neoplastic tubular pattern proliferation with cystic multifocal formation [HE Obj. 200x]. B- Cystic endometrial hyperplasia. Multiple dilated endometrial glands filled by eosinophilic amorphous material [HE Obj. 100x].

strongly suggestive of the disease, associated with a negative LDDST, followed by an elevated 17-OHP post-ACTH [1,2]. Moreover, Yorkshire Terrier is one of the most affected breeds with HAC in this region [15].

Granulosa cell tumor diagnose was provided only after exploratory laparotomy and histopathologic ovarian evaluation once this diagnostic approach is not possible by means of imaging [10]. Cystic endometrial hyperplasia diagnosed after surgery is a common paraneoplastic syndrome related to granulosa cell tumors and is a frequent progesterone-related uterine disease in bitches $[6,8]$. The elevated 17-OHP concentration in this case supports an influence of the hormonal secretion profile of the tumor in endometrium leading to cystic hyperplasia.

Despite bilateral adrenal gland hyperplasia, the absence of post-mortem examination impeded pituitary adenoma investigation, or an eventual bilateral adrenocortical neoplasia. The LDDST response profile in this case was not compatible with functional adrenocortical neoplasia $[2,7,8]$ and the documentation of bilateral enlargement by itself is not consistent with HAC. Adrenomegaly may be secondary to chronic activation of the hypothalamic-pituitary-adrenal axis secondary to chronic or degenerative diseases [2,7], as for example, a large abdominal neoplasia as documented in the present case. In contrast, exogenous progestins promote corticotrophic negative feedback $[2,8]$. Whether endogenous progesterone overproduction would have the same effect, or negatively affect LDDST sensibility is unknow [2]. Likewise, the hypoadrenocorticism clinical picture, and deficient cortisol response in the AST two weeks after surgery, with trilostane treatment maintenance, give support to the granulosa cell tumor promoting a clinical HAC hypothesis due to the altered ovarian steroidogenesis.
A common trilostane side effect is hyperkalemia, independently of aldosterone suppression [9] as documented in the present case. Even though sodium to potassium ratio below 27:1 suggests mineralocorticoid deficiency, sodium concentration nearby the upper reference range dismiss this hypothesis, once aldosterone deficiency is marked by hyperkalemia associated with hyponatremia [7,8]. Moreover, patients that suffer unilateral adrenalectomy for ACTH-independent HAC do not develop mineralocorticoid deficiency after surgery $[7,8]$, a similar pathophysiologic scenario described herein. This argument is supported by the fact that the hypoadrenocorticism documented after surgery was marked by glucocorticoid deficiency after ovarian removal, and trilostane treatment maintenance. A recent cohort study on patients that developed hypoadrenocorticism secondary to trilostane therapy did show that most patients last two or more years for this outcome [11]. Furthermore, rarely those reported cases occurred after only few weeks after trilostane starting as observed in the present case, despite some dogs did show hypoadrenocorticism only five days after therapy beginning [11]. Once AST performed before surgery showed that cortisol level were higher then desired, and that no trilostane change was proposed based on that, hypoadrenocorticism occurrence after surgery further indicate the granulosa cell tumor as the rascal.

\section{MANUFACTURERS}

${ }^{1}$ Dechra Veterinary Products. Northwich, UK.

${ }^{2}$ Novartis Pharma. São Paulo, SP, Brazil.

Declaration of interest. The authors report no conflicts of interest. The authors alone are responsible for the content and writing of the paper. 


\section{REFERENCES}

1 Behrend E.N. \& Kennis R. 2010. Atypical Cushing's syndrome in dogs: arguments for and against. Veterinary Clinics of North America: Small Animal Pratice. 40(2): 285-296.

2 Behrend E.N., Kooistra H.S., Nelson R., Reusch C.E. \& Scott-Moncrieff J.C. 2013. Diagnosis of spontaneous canine hyperadrenocorticism: 2012 ACVIM consensus statement (small animal). Journal of Veterinary Internal Medicine. 27: 1292-1304.

3 Behrend E.N. \& Melian C. 2013. Hyperadrenocorticism in Dogs. In: Rand J. (Ed). Clinical Endocrinology of Companion Animals. Ames: Wiley-Blackwell, pp.43-64.

4 Bolson L. \& Pachaly J.R. 2004. Hiperestrogenismo secundário a tumor ovariano em cadela. Arquivos de Ciências Veterinárias e Zoologia da UNIPAR. 7(2): 175-179.

5 Brömel C., Feldman E.C., Davidson A.P., Nelson R.W., Kass P.L., Vico A.E., Labelle P., Munro C.J. \& Conley A.J. 2010. Serum 17 $\alpha$-hydroxyprogesterone concentrations during the reproductive cycle in healthy dogs and dogs with hyperadrenocorticism. Journal of the American Veterinary Medical Association. 236 (11): 1208-1214.

6 Daleck C.R. \& Nardi A.B. 2016. Neoplasias do Sistema Reprodutivo Feminino. In: Oncologia em Cães e Gatos. Rio de Janeiro: Roca, pp.545-555.

7 Feldman E.C., Nelson R.W., Reusch C. \& Scott-Moncrieff J.C. 2015. Canine and Feline Endocrinology. 4th edn. Saint Louis: Saunders, 688p.

8 Galac S., Reusch C.E., Kooistra H.S. \& Rijnberk A. 2013. Adrenais. In: Rijnberk A. \& Kooistra H.S. (Eds). Endocrinologia Clínica de Cães e Gatos. 2.ed. São Paulo: Roca, pp.101-165.

9 Griebsch C., Lehnert C., Williams G.J., Failing K. \& Neiger R. 2014. Effect of trilostane on hormone and serum electrolyte concentrations in dogs with pituitary-dependent hyperadrenocorticism. Journal of Veterinary Internal Medicine. 28: 160-165.

10 Grooters A.M. 2003. Ovariopatias e Uteropatias. In: Bichard S.J. \& Sherding R.G. (Eds). Manual Saunders: Clínica de Pequenos Animais. 2.ed. São Paulo: Roca, pp.1114-1128.

11 King J.B. \& Morton J.M. 2017. Incidence and risk factors for hypoadrenocorticism in dogs treated with trilostane. The Veterinary Journal. 230: 24-29.

12 Maschietto L.A. 2007. Perfil de esteroides sexuais em cães com hiperadrenocorticismo - aspectos de diagnóstico e correlações clínicas. 88f. São Paulo, SP. Dissertação (Mestrado em Medicina Veterinária) - Programa de Pós-graduação em Clínica Veterinária, Universidade de São Paulo.

13 Nelson R.W. \& Couto C.G. 2015. Medicina Interna de Pequenos Animais. 5.ed. Rio de Janeiro: Elsevier, 1512p.

14 Nichols J., Warren J.C. \& Mantz F.A. 1962. ACTH-like excretion from carcinoma of the ovary - the clinical effect of m,p'-DDD. Journal of the American Medical Association. 182(7): 133-138.

15 Pöppl A.G., Coelho I.C., Silveira C.A., Moresco M.B. \& Carvalho G.L.C. 2016. Frequency of endocrinopathies and characteristics of affected dogs and cats in southern brazil (2004-2014). Acta Scientiae Veterinariae. 44: 1379.

16 Romão F., Leitão L., Machado L., Lourenço M., Mamprim M. \& Cristina M. 2011. Hiperadrenocorticismo em cães. Clínica Veterinária. 91: 86-92.

17 Yamini B., VanDenBrink P.L. \& Refsal K.R. 1997. Ovarian steroid cell tumor resembling luteoma associated with hyperadrenocorticism (cushing's disease) in a dog. Veterinary Pathology. 34(1): 57-60.

18 Young R.H. \& Scully R.E. 1987. Ovarian steroid cell tumor associated with Cushing's syndrome: a report of tree cases. International Journal of Gynecological Pathology. 6(1): 40-48. 